\title{
Hydrophobic Moieties Bestow Fast-Folding and Hyperstability on Collagen Triple Helices
}

\section{Journal Article}

Author(s):

Egli, Jasmine; Siebler, Christiane; Köhler, Martin; Zenobi, Renato (D); Wennemers, Helma

Publication date:

2019-04-10

Permanent link:

https://doi.org/10.3929/ethz-b-000338835

Rights / license:

In Copyright - Non-Commercial Use Permitted

Originally published in:

Journal of the American Chemical Society 141(14), https://doi.org/10.1021/jacs.8b13871

Funding acknowledgement:

178805 - Synthetic Collagen (Fortsetzung) (SNF) 


\title{
Hydrophobic Moieties Bestow Fast-Folding and Hyperstability on Collagen Triple Helices
}

\author{
Jasmine Egli, Christiane Siebler, Martin Köhler, Renato Zenobi, and Helma Wennemers* \\ Laboratory of Organic Chemistry, ETH Zurich, D-CHAB, Vladimir-Prelog-Weg 3, Zurich 8093, Switzerland
}

\begin{abstract}
Trans amide bonds and fast cis-trans isomerization of Xaa-Pro bonds are crucial for the stability and folding rate of collagen, the most abundant protein in mammals. Here, we explored the effect of pendant hydrophobic moieties on the folding and stability of collagen triple helices. Kinetic studies with a series of collagen model peptides showed that a local hydrophobic environment accelerates cis-trans isomerization to an extent that thermally induced unfolding and folding of the collagen triple helix take place at the same speed. Thermal denaturation studies revealed that the hydrophobic appendages provide hyperstable collagen triple helices $\left(T_{m}=70^{\circ} \mathrm{C}\right)$.
\end{abstract}

Collagen is the most abundant protein in mammals and provides stability to biomaterials such as skin, tendons, and bones. ${ }^{1-3}$ The fibrous protein comprises three parallel, lefthanded polyproline II (PPII)-like single strands that assemble into a right-handed triple helix with a one-residue stagger. The single strands consist of Xaa-Yaa-Gly repeat units where proline (Pro, $\mathrm{P}$ ) residues are most common in the Xaa positions and (4R)-4-hydroxyproline (Hyp, O) residues in the Yaa positions (Figure 1a). ${ }^{1-3}$ All amide bonds within the single strands need to be trans configured to allow the formation of the triple helix. Thus, the higher the trans:cis ratio of the Xaa-Pro bonds in the collagen single strands, the more stable is the resulting triple helix. ${ }^{1}$ Moreover, cis-trans isomerization of the tertiary amide bonds is the rate limiting step in collagen folding. ${ }^{3-5}$ Since this isomerization is slow in aqueous media $\left(k \sim 10^{-3}-10^{-5} \mathrm{~s}^{-1}\right)$ a strong hysteresis is characteristic for, e.g., thermally induced unfolding and refolding of collagen triple helices. ${ }^{3,5-7}$ Nature uses cis-trans prolyl isomerases to accelerate the amide bond isomerization and thus accelerate triple helix formation. 5

Synthetically accessible collagen model peptides (CMPs) have served as valuable tools to elucidate the structural features responsible for the stability of collagen. ${ }^{1,9,10}$ In addition, they hold great promise for the development of biocompatible materials but suffer from slow folding and comparably low thermal stability.,11,12 Tools that enhance the stability of collagen triple helices and accelerate folding are therefore important for a better understanding of collagen folding and applications of CMPs as biocompatible materials.

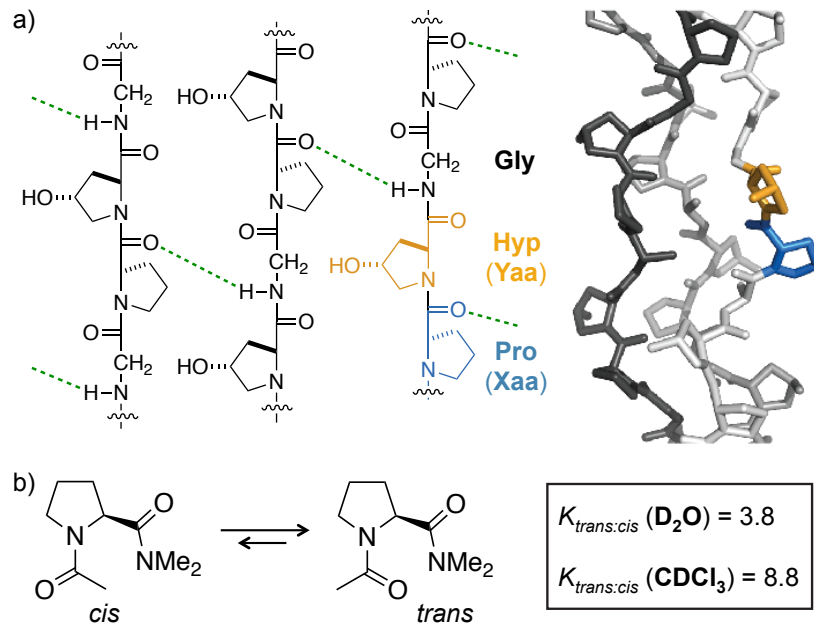

Figure 1. a) General structure of collagen. b) Trans and cis conformers of Ac-Pro- $\mathrm{NMe}_{2}$ and $K_{\text {trans:cis }}$ values in $\mathrm{D}_{2} \mathrm{O}$ and $\mathrm{CDCl}_{3}$.

We have recently found that the trans:cis isomer ratio of Xaa-Pro bonds is typically higher in organic solvents compared to water. ${ }^{13}$ For example, the $K_{\text {trans:cis }}$ of Ac-Pro$\mathrm{NMe}_{2}$ is 8.8 in $\mathrm{CDCl}_{3}$ and only 3.8 in $\mathrm{D}_{2} \mathrm{O}$ (Figure $1 \mathrm{~b}$ ). CMPs should therefore form more stable collagen triple helices in a hydrophobic environment than in water. However, little is known about the influence of the environment on the stability and folding rate of the collagen triple helix since CMPs have limited solubility in non-aqueous solvents. ${ }^{14}$ We envisioned that a hydrophobic microenvironment should favor trans amide bonds within CMP single strands and therefore stabilize collagen triple helices.

Herein we present CMPs bearing hydrophobic moieties that form hyperstable collagen triple helices in water. Moreover, we show that a hydrophobic environment accelerates the cis-trans isomerization of Xaa-Pro bonds to such an extent that the collagen triple helix folds and unfolds at the same speed.

We reasoned that a local hydrophobic environment could be created around collagen triple helices by covalently attaching fatty acids or other hydrophobic moieties to CMPs. Furthermore, we envisioned that the attachment of only one hydrophobic group within a 21-mer CMP would maintain solubility in water and suffice to 
generate hydrophobic patches around the collagen triple helix. We therefore started our investigations by synthesizing CMPs 1-5 that contain different covalently attached hydrophobic residues in the middle repeat unit of a 21-mer (Figure 2). We chose (4R)-configured amidoproline residues in the Xaa position as anchors for the hydrophobic tails since substituents at this site point to the outside of the collagen triple helix and do not interfere with triple helix formation. ${ }^{15}$ Fatty acids (CMPs 2 and 3 ), a cholesterol derivative (CMP 4) and Disperse Red with aromatic moieties (CMP 5) were used as hydrophobic residues. CMP 1 with a methyl group in place of the hydrophobic tail served as reference compound. ${ }^{16}$ The fatty acids and cholesterol were chosen as common but structurally different natural lipids and Disperse Red as a hydrophobic aromatic molecule.
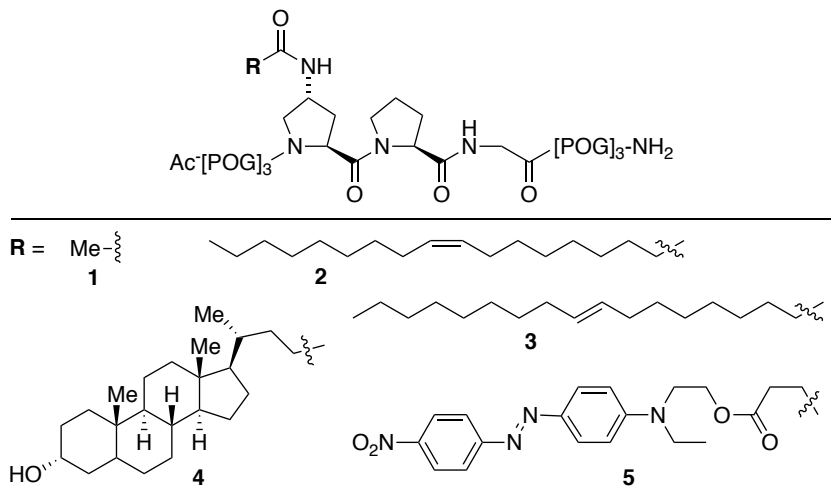

Figure 2. CMPs 1-5 bearing different hydrophobic moieties.

Circular dichroism (CD) spectra of aqueous solutions of CMPs 1-5 show a maximum at $224 \mathrm{~nm}$ and a minimum at around $200 \mathrm{~nm}$ that are characteristic for the collagen triple helix (Figure 3a). ${ }^{1,10}$ Thermal denaturation experiments with CD spectroscopy as a monitoring tool resulted in sigmoidal curves that are typical for cooperative unfolding transitions of collagen triple helices (Figure $3 b$ ). ${ }^{6}$ Fitting of the data to a two-state model provided midpoints of the thermal transition $\left(T_{m}\right)$, which are a good measure for the relative stability of the triple helices (Figure $3 b$ ). ${ }^{10}$
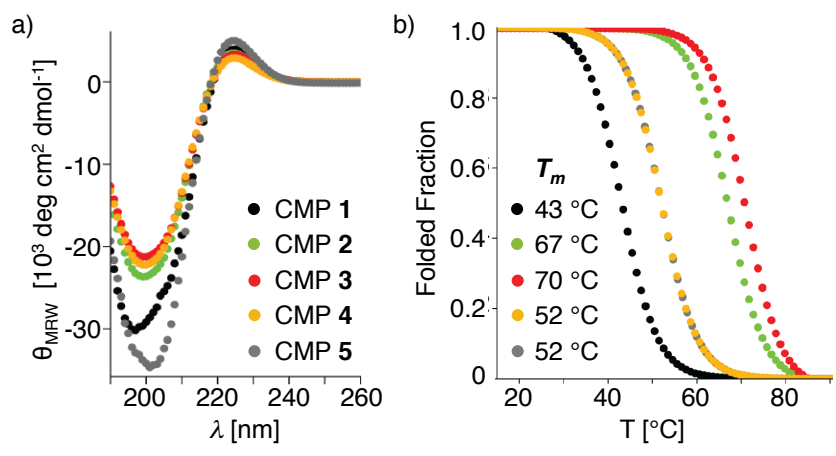

Figure 3. a) CD spectra of triple helices formed by CMPs 1-5 in $\mathrm{H}_{2} \mathrm{O}(0.2 \mathrm{mM})$. b) Folded fractions of thermal denaturation curves of the triple helices, monitored at $224 \mathrm{~nm}$.

All of the triple helices formed from the CMPs 2-5 with a hydrophobic moiety are more stable compared to the triple helices derived from CMP 1. Attachment of conformationally flexible oleic acid increased the $T_{m}$ values even up to $\sim 70{ }^{\circ} \mathrm{C}$ (CMPs 2 and 3 ). ${ }^{17}$ These are extraordinarily high $T_{m}$ values for triple helices derived from CMPs that contain 21 amino acids and only a single modification. Comparable stabilities have only been observed with covalently cross-linked CMPs or CMPs covalently linked to a tripodal template. ${ }^{18,19}$ Noteworthy, molecular modeling studies with CMP 3 suggest that the $\mathrm{C}_{18}$ alkyl chain can only cover a small fraction $(<20 \%)$ of the surface area of the collagen triple helix. ${ }^{20}$ Thus, a relatively small local hydrophobic environment increases the thermal stability of collagen triple helices significantly.

Hydrophobic moieties can form unspecific aggregates in aqueous environment that could interfere with triple helix formation. Despite the low maximal coverage of the collagen triple helices by the hydrophobic moieties, we used NMR spectroscopy, dynamic light scattering, and native mass spectrometry (MS) to ascertain that the CMPs do indeed form triple helices. We recorded a ${ }^{1} \mathrm{H},{ }^{15} \mathrm{~N}$-HSQC spectrum with the ${ }^{15} \mathrm{~N}$-labelled derivative AcPOGPOGPOGXPGPOGPOGPOG-NH $\mathrm{N}_{2}$ (3a) of CMP 3 where $\underline{G}$ represents ${ }^{15} \mathrm{~N}$-labelled Gly and $\mathbf{X}$ the trans-oleic acid functionalized aminoproline residue. The one-residue stagger of the collagen triple helix places each of the labeled Gly residues at the $\mathrm{N}$ - and C-termini in a different chemical environment. Thus, six signals are expected in the spectrum upon triple helix formation for the labeled Gly residues at the $\mathrm{N}$ - and $\mathrm{C}$-terminal ends of $\mathbf{3} \mathbf{a} .{ }^{21}$ In contrast, only two signals are expected for denatured, single stranded CMP 3a. The ${ }^{1} \mathrm{H},{ }^{15} \mathrm{~N}-\mathrm{HSQC}$ spectrum of CMP 3a shows at room temperature signals that are indicative of a triple helix and only two that are indicative of the single stranded CMP upon heating to $70{ }^{\circ} \mathrm{C}$ (Figure 4a)..$^{21,22}$ Dynamic light scattering studies with CMPs 1-4 verified triple helix formation and revealed that the triple helices - including those derived from non-amphiphilic CMP 1 - form also higher aggregates (Figure S8). ${ }^{20,23}$ Triple helix formation was further confirmed by native electrospray ionization MS and ion mobility spectrometry ${ }^{24}$ which showed the mass of the trimer and the expected drift time (Figure $4 \mathrm{~b}$ ). ${ }^{20}$ These findings show that the hydrophobic moiety of the examined CMPs does not impede but instead stabilizes collagen triple helices.
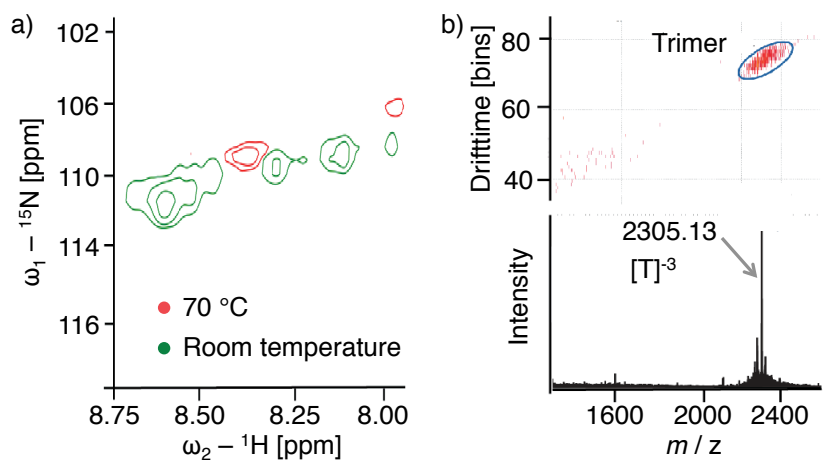

Figure 4. a) ${ }^{1} \mathrm{H},{ }^{15} \mathrm{~N}$-HSQC spectrum of the ${ }^{15} \mathrm{~N}$-labelled collagen triple helix formed by CMP 3a at room temperature (green) and single stranded CMP 3a at $70{ }^{\circ} \mathrm{C}$ (red). b) Native MS: Ion mobility mass spectrum (upper) and mass spectrum (lower) of the 
triply negatively charged trimer of CMP 3 [T] in aqueous solution.

Next, we explored whether the hydrophobic moieties around the collagen triple helices affect the unfolding and folding rates upon heating and cooling. The cis-trans isomerization of the tertiary amide bonds is rate-limiting for collagen folding but difficult to monitor for the amide groups within a 21-mer CMP. We therefore started by determining the rate constants for the cis-trans isomerization of the model proline derivative Ac-Pro- $\mathrm{NMe}_{2}$ in organic solvents (dioxane, chloroform, DMSO) and water. ${ }^{25}$ Inversion-transfer NMR experiments revealed that the isomerization rates depend significantly on the environment (Figure 5). The tertiary amide bond isomerizes faster in aprotic compared to aqueous medium, e.g., the cis-to-trans isomerization in dioxane is approximately 35 times faster than in $\mathrm{D}_{2} \mathrm{O}$. We therefore envisioned that the hydrophobic environment accelerates cis-trans isomerization in CMPs $\mathbf{2 - 4}$ and thereby the formation of the triple helices.

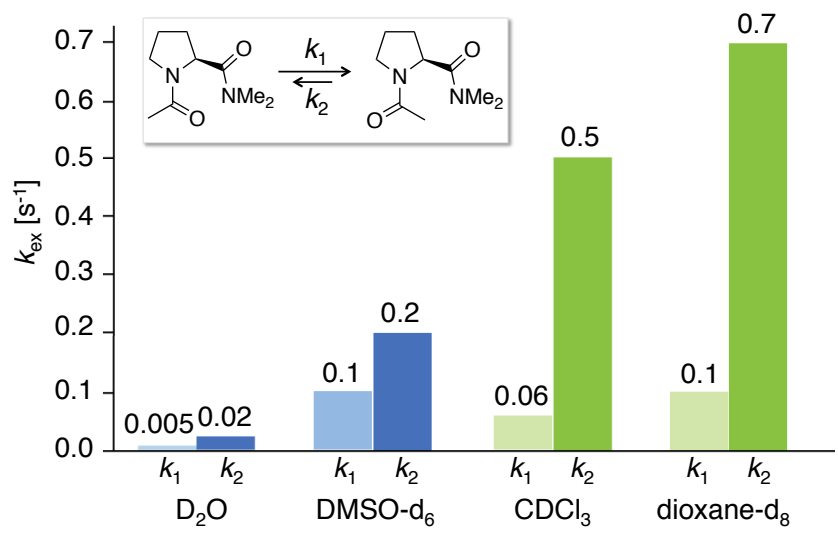

Figure 5. First-order reaction constants of cis-trans isomerization of Ac-Pro- $\mathrm{NMe}_{2}$ in different solvents at $40{ }^{\circ} \mathrm{C}$.

To explore this hypothesis, the aqueous solutions of CMPs 1-5 were repeatedly heated and cooled with a rate of $1{ }^{\circ} \mathrm{C} / 100 \mathrm{~s}$ while monitoring the signal at $224 \mathrm{~nm}$ by $\mathrm{CD}$ spectroscopy. For CMP 1 that does not bear a hydrophobic moiety, a significantly faster unfolding than folding of the triple helix was observed (Figure 6a, left). Such a hysteresis is typical for the folding of collagen and reflects the slow cis-trans isomerization of the tertiary amide bonds, which limits the folding. ${ }^{6}$ In contrast, the denaturation and refolding of the triple helices derived from CMPs 2-5 takes place at the same rate (Figure 6a, right). These are to the best of our knowledge the first examples of collagen triple helices, formed by the self-assembly of three individual strands, that fold and unfold at the same speed at a heating/cooling rate of $1{ }^{\circ} \mathrm{C} / 100 \mathrm{~s}^{26}$

Finally, we determined the relative rates at which CMPs 1-5 form triple helices by temperature "jump" experiments. Solutions of CMP 1-5 were denatured by heating at $90^{\circ} \mathrm{C}$ for at least $30 \mathrm{~min}$ and then cooled to $7^{\circ} \mathrm{C}$. Upon cooling, the recovery of the ellipticity at $224 \mathrm{~nm}$ was monitored by CD spectroscopy over time after a dead time of $2 \mathrm{~min}^{27}$
These experiments provided the time at which $50 \%$ of the total ellipticity was recovered $\left(t_{1 / 2}\right)$, the time at which half of the peptides reassembled into triple helices (Figure 6b). The $t_{1 / 2}$ values of CMPs $\mathbf{2}-\mathbf{5}$ with hydrophobic moieties are significantly smaller $\left(t_{1 / 2}<2-4.0 \mathrm{~min}\right)$ compared to that of
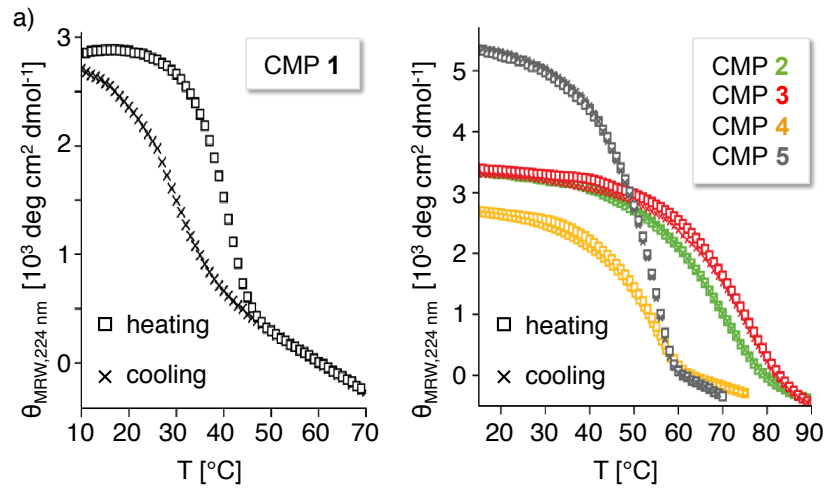

b)

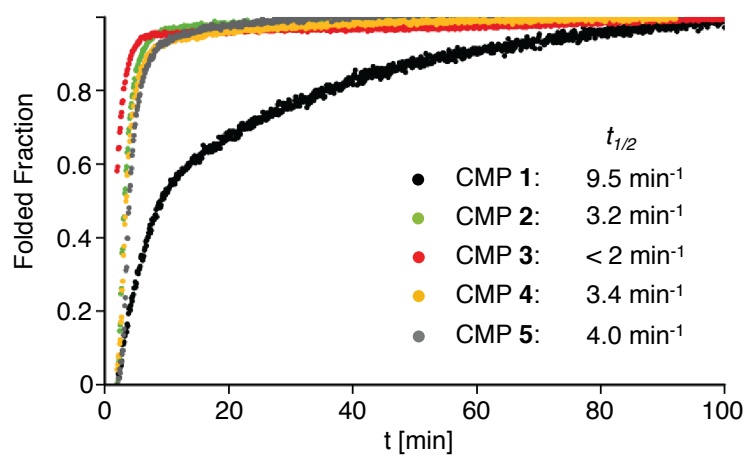

Figure 6. a) Thermal denaturation and folding of triple helices derived from CMP 1 (left) and CMP 2-5 (right) in nanopure $\mathrm{H}_{2} \mathrm{O}$ $(0.2 \mathrm{mM})$, heating/cooling rate of $1{ }^{\circ} \mathrm{C} / 100 \mathrm{~s}$; b) CD spectroscopic monitoring $(\lambda=224 \mathrm{~nm})$ of triple helix folding upon cooling solutions of CMP $1-5$ from $90^{\circ} \mathrm{C}$ to $7^{\circ} \mathrm{C}$ in nanopure $\mathrm{H}_{2} \mathrm{O}$ $(0.2 \mathrm{mM})$.

CMP $1\left(t_{1 / 2}=9.5 \mathrm{~min}\right)$. CMP 3 folded the fastest with a $t_{1 / 2}$ value below $2 \mathrm{~min}$, which was the limit for the first measurement. ${ }^{27}$ Noteworthy, the folding speed of the CMPs correlates with the thermal stability of the resulting triple helices, e.g., the most stable triple helix, which was formed by CMP $3\left(T_{\mathrm{m}}=70^{\circ} \mathrm{C}\right)$, also folded the fastest $\left(t_{1 / 2}<2 \mathrm{~min}\right)$.

In summary, we have developed fast-folding and hyperstable collagen triple helices by attaching hydrophobic moieties to single stranded CMPs. The hydrophobic environment accelerates the cis-trans isomerization of the backbone Xaa-Pro amide bonds to an extent that triple helices fold and unfold at the same speed. This is remarkable since collagen folds otherwise significantly slower than it unfolds. The hydrophobic "glue" also endows the collagen triple helix with exquisite thermal stability. These findings suggest that hydrophobic regions might also help the folding of natural collagen ${ }^{28}$ and open exciting new opportunities for the development of fast-folding synthetic collagen-based materials.

\section{ASSOCIATED CONTENT} Supporting Information 
Details on the syntheses and analyses of the presented compounds. This material is available free of charge via the Internet at http://pubs.acs.org.

\section{AUTHOR INFORMATION Corresponding Author}

*Helma.Wennemers@org.chem.ethz.ch ORCID: 0000-0002-3075-5741

\section{Notes}

The authors declare no competing financial interests.

\section{ACKNOWLEDGMENT}

We thank the Swiss National Science Foundation (grant 200020 178805) for financial support. We thank Dr. M.-O. Ebert and the NMR Service of the Laboratory of Organic Chemistry as well as the MoBiAs Platform of D-CHAB for support.

\section{REFERENCES}

(1) Shoulders, M. D.; Raines, R. T. Collagen structure and stability. Annu. Rev. Biochem. 2009, 78, 929-958.

(2) Bella, J. Collagen structure: new tricks from a very old dog. Biochem. J. 2016, 473, 1001-1025.

(3) Engel, J.; Bächinger, H. P. Structure, stability and folding of the collagen triple helix. Top. Curr. Chem. 2005, 247, 7-33.

(4) Bächinger, H. P.; Bruckner, P.; Timpl, R.; Prockop, D. J.; Engel, J. Folding Mechansim of the Triple Helix in Type-III Collagen and Type-III pN-Collagen: Role of Disulfide Bridges and Peptide Bond Isomerization. Eur. J. Biochem. 1980, 106, 619-632.

(5) Fischer, G. Chemical aspects of peptide bond isomerization. Chem. Soc. Rev. 2000, 29, 119-127.

(6) (a) Davis, J. M.; Bächinger, H. P. Hysteresis in the triple helixcoil transition of type III collagen. J. Biol. Chem. 1993, 268, 2596525972. (b) Mizuno, K.; Boudko, S. P.; Engel, J.; Bächinger, H. P. Kinetic hysteresis in collagen folding. Biophys. J. 2010, 98, 30043014.

(7) Grathwohl, C.; Wüthrich, K. Nmr studies of the rates of proline cis-trans isomerization in oligopeptides. Biopolymers 1981, 20, 2623 2633.

(8) (a) Bächinger, H. P. The Role of Cis-Trans Isomerization of Peptide Bonds in the Coil-Triple Helix Conversion of Collagen. Eur. J. Biochem. 1978, 90, 605-613. (b) Fischer, G.; Wittmann-Liebold, B.; Lang, K.; Kiefhaber, T.; Schmid, F. X. Cyclophilin and peptidylprolyl cis-trans isomerase are probably identical proteins. Nature 1989, 337,476

(9) Siebler, C.; Erdmann, R. S.; Wennemers, H. From azidoproline to functionalizable collagen. Chimia 2013, 67, 891-895.

(10) For examples, see: (a) Holmgren, S. K.; Taylor, K. M.; Bretscher, L. E.; Raines, R. T. Code for collagen's stability deciphered. Nature 1998, 392, 666. (b) Bretscher, L. E.; Jenkins, C. L.; Taylor, K. M.; DeRider, M. L.; Raines, R. T. Conformational stability of collagen relies on a stereoelectronic effect. J. Am. Chem. Soc. 2001, 123, 777-778. (c) Cadamuro, S. A.; Reichold, R.; Kusebauch, U.; Musiol, H.-J.; Renner, C.; Tavan, P.; Moroder, L. Conformational properties of 4-mercaptoproline and related dervatives. Angew. Chem. Int. Ed. 2008, 47, 2143-2146. (d) Shoulders, M. D.; Satyshur, K. A.; Forest, K. T.; Raines, R. T. Stereoelectronic and steric effects in side chains preorganize a protein main chain. Proc. Natl. Acad. Sci. 2010, 107, 559-564. (e) Zhang, Y.; Malamakal, R. M.; Chenoweth, D. M. Aza-glycine induces collagen hyperstability. J. Am. Chem. Soc. 2015, 137, 12422-12425. (f) Erdmann, R. S.; Wennemers, H. Functionalizable collagen model peptides. J. Am. Chem. Soc. 2010, 132, 13957-13959. (g) Siebler, C.;
Erdmann, R. S.; Wennemers, H. Switchable proline derivatives: tuning the conformational stability of the collagen triple helix by $\mathrm{pH}$ changes. Angew. Chem. Int. Ed. 2014, 53, 10340-10344. (h) Egli, J.; Siebler, C.; Maryasin, B.; Erdmann, R. S.; Bergande, C.; Ochsenfeld, C.; Wennemers, H. pH-Responsive Aminoproline-Containing Collagen Triple Helices. Chem. Eur. J. 2017, 23, 7938-7944.

(11) (a) Chattopadhyay, S.; Raines, R. T. Review collagen-based biomaterials for wound healing. Biopolymers 2014, 101, 821-833. (b) Strauss, K.; Chmielewski, J. Advances in the design and higher-order assembly of collagen mimetic peptides for regenerative medicine. Curr. Opin. Biotechnol. 2017, 46, 34-41. (c) Moore, A. N.; Hartgerink, J. D. Self-assembling multidomain peptide nanofibers for delivery of bioactive molecules and tissue regeneration. Acc. Chem. Res. 2017, 50, 714-722.

(12) For examples, see: (a) Kotch, F. W.; Raines, R. T. Selfassembly of synthetic collagen triple helices Proc. Natl. Acad. Sci. U. S. A. 2006, 103, 3028-3033. (b) Sarkar, B.; O'Leary, L. E. R.; Hartgerink, J. D. Self-assembly of fiber-forming collagen mimetic peptides controlled by triple-helical nucleation. J. Am. Chem. Soc. 2014, 136, 14417-14424. (c) Tanrikulu, I. C.; Forticaux, A.; Jin, S.; Raines, R. T. Peptide tessellation yield micrometer-scale collagen triple helices. Nat. Chem. 2016, 8,1008 .

(13) Siebler, C.; Maryasin, B.; Kümin, M.; Erdmann, R. S.; Rigling, C.; Grünenfelder, C.; Ochsenfeld, C.; Wennemers, H. Importance of dipole moments and ambient polarity for the conformation of Xaa-Pro moieties - a combined experimental and theoretical study. Chem. Sci. 2015, 6, 6725-6730.

(14) (a) Engel, J.; Chen, H. T.; Prokop, D. J.; Klump, H. The triple helix-coil conversion of collagen-like polytripeptides in aqueous and nonaqueous solvents. Comparison of the thermodynamic parameters and the binding of water to (L-Pro-L-Pro-Gly)n and (L-Pro-L-HypGly)n. Biopolymers 1977, 16, 601-622. (b) Horng, J.-C.; Kotch, F. W.; Raines, R. T. Is glycine a surrogate for a D-amino acid in the collagen triple helix?. Protein Sci. 2007, 16, 208-215. (c) Lorenz, L.; Kusebauch, U.; Moroder, L.; Wachtveitl, J. Temperature- and Photocontrolled Unfolding/Folding of a Triple-Helical AzobenzeneStapled Collagen Peptide Monitored by Infrared Spectroscopy. ChemPhysChem 2016, 17, 1314-1320.

(15) Erdmann, R. S.; Wennemers, H. Effect of sterically demanding substituents on the conformational stability of the collagen triple helix. J. Am. Chem. Soc. 2012, 134, 17117-17124.

(16) CMPs with two hydrophobic moieties were not soluble in water.

(17) A triple helix formed by a CMP bearing a $\mathrm{C}_{12}$ alkyl chain has only a $T_{m}$ value of $39^{\circ} \mathrm{C}$ suggesting that the hydrophobic moiety needs to be sufficiently long to create a hydrophobic microenvironment.

(18) Hentzen, N.B.; Smeenk, L. E.; Witek, J.; Riniker, S. Wennemers, H. Cross-linked collagen triple helices by oxime ligation. J. Am. Chem. Soc. 2017, 139, 12815-12820.

(19) (a) Feng, Y.; Melacini, G.; Taulane, J. P.; Goodman, M. Acetyl-terminated and template-assembled collagen-based polypeptides composed of Gly-Pro-Hyp sequences. J. Am. Chem. Soc. 1996, 118, 10351-10358. (b) Horng, J.-C.; Hawk, A. J.; Zhao, Q.; Benedict, E. S.; Burke, S. D.; Raines, R. T. Macrocyclic scaffold for the collagen triple helix. Org. Lett. 2006, 8, 4735-4738.

(20) See the supporting information for details.

(21) (a) Liu, X.; Kim, S.; Dai, Q.-H.; Brodsky, B.; Baum, J. Nuclear magnetic resonance shows asymmetric loss of triple helix in peptides modeling a collagen mutation in brittle bone disease. Biochemistry 1998, 37, 15528-15533. (b) Fallas, J.; Hartgerink, J.-D. Computational design of self-assembling register-specific collagen heterotrimers. Nat. Commun. 2012, 3, 1087. (c) Acevedo-Jake, A. M.; Jalan, A. A.; Hartgerink, J. D. Comparative NMR analysis of collagen triple helix organization from $\mathrm{N}$-to $\mathrm{C}$-termini. Biomacromolecules 2015, 16, 145-155. 
(22) Similar chemical environments of ${ }^{15} \mathrm{~N}$-labels in collagen triple helices can lead to overlap of the ${ }^{15} \mathrm{~N}$-Gly signals of the three strands, ref. 21c. The Gly residue at the C-terminally labelled POG unit lacks a H-bonding partner within the triple helix. This region is therefore expected to be the least defined within the triple helix, likely causing the observed overlap of the signals furthest downfield.

(23) For previous studies on aggregates formed by collagen triple helices, see: Kar, K.; Amin, P.; Bryan, M. A.; Persikov, A. V.; Mohs, A.; Wang, Y.-H.; Brodsky, B. Self-association of collagen triple helices into higher order structures. J. Biol. Chem. 2006, 281, 3328333290 .

(24) (a) Loo, J. Studying noncovalent protein complexes by electronspray ionization mass spectrometry. Mass. Spectrom. Rev. 1997, 16, 1-23. (b) Ganem, B.; Li, Y. T.; Henion, J. D. Detection of noncovalent receptor-ligand complexes by mass spectrometry. $\mathrm{J}$. Am. Chem. Soc. 1991, 113, 6294-6296. (c) Boeri Erba, E.; Barylyuk, K.; Yang, Y.; Zenobi, R. Quantifying protein-protein interactions within noncovalent complexes using electronspray ionization mass spectrometry. Anal. Chem. 2011, 83, 9251-9259. For a mass spectrometric study on collagen, see: (d) Lalande, M.; CombyZerbino, C.; Bouakil, M.; Dugourd, P.; Chirot, F.; Poully, J.-C.
Isolated collagen mimetic peptide assemblies have stable triple-helix structures. Chem. Eur. J. 2018, 52, 13728-13733.

(25) For related studies, see: (a) Eberhardt, E. S.; Loh, S. N.; Hinck, A. P.; Raines, R. T. Solvent effects on the energetics of prolyl peptide bond isomerization. J. Am. Chem. Soc. 1992, 114, 5437-5439. (b) Kramer, M. L.; Fischer, G. FKBP-like catalysis of peptidyl-prolyl bond isomerization by micelles and membrane. Biopolymers 1997, 42, 49-60.

(26) Even at a heating rate of $1{ }^{\circ} \mathrm{C} / 20 \mathrm{sec}$, the fastest possible with the CD spectrometer, no hysteresis was observed. Even covalently cross-linked triple helices exhibit hysteresis upon cooling and heating at a heating rate of $1^{\circ} \mathrm{C} / 100 \mathrm{~s}$ (Figure S5).

(27) The sample was heated at $90^{\circ} \mathrm{C}$ for $30-60 \mathrm{~min}$ and then immediately transferred to a $1-\mathrm{mm}$ cuvette that had been pre-cooled at $7^{\circ} \mathrm{C}$. The sample had reached $7^{\circ} \mathrm{C}$ after $2 \mathrm{~min}$ (dead time) and the refolding was monitored.

(28) Latvanlehto, A.; Snellman, A.; Tu, H.; Pihlajaniemi, T. Type XIII collagen and some other transmembrane collagens contain two separate coiled-coil motifs, which may function as independent oligomerization domains. J. Biol. Chem. 2003, 278, 37590-37599. 
Suggested Table of Content Graphic:

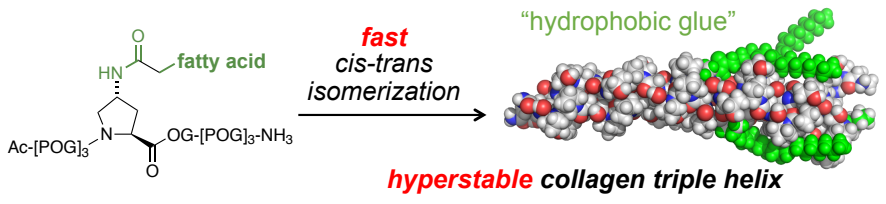

